\title{
Feed-In Tariff Personal Carbon Allowance: A Case Study of Psychological Change
}

\author{
Takayoshi Kitamura, Asao Takamatsu, Hirotake Ishii, and Hiroshi Shimoda \\ Graduate School of Energy Science, Kyoto University, Kyoto, Japan \\ \{kitamura, takamatsu, hirotake, shimoda\}@ei.energy.kyoto-u.ac.jp
}

\begin{abstract}
The scheme of Personal Carbon Allowance (PCA) system which has been under discussion in United Kingdom is one of the innovative policies which have the potential to solve energy and climate issues. The authors have been proposed Feed-in Tariff PCA (FIT-PCA) as a suitable policy for Japan. The main purpose of this scheme is to encourage citizens to manage their $\mathrm{CO}_{2}$ emissions from their daily lives, furthermore, it is expected to improve their attitudes to global environmental issues. In the psychological model to express their behavioral changes, it is assumed that the experience of FIT-PCA causes loss aversion, goal setting and eudaimonia, and they change their life styles to pro-environmental ones. In this study, a case study has been conducted for half a year in cooperation with 30 households to investigate the validity of the model and the change of their energy reduction behaviors and attitudes to global environmental issues.
\end{abstract}

Keywords: social system, case study, personal carbon allowances, energy issues, psychological changes.

\section{Introduction}

In Japan, reduction of $\mathrm{CO}_{2}$ emission towards realization of a low-carbon society has been progressing in the industrial sector. On the other hand, in the household sector, it has not progressed enough [1]. Personal carbon allowances (PCA) system is the policy in which the government distributes the right to emit $\mathrm{CO}_{2}$ to citizens and manage them [2]. The PCA system has been studied mainly in the $\mathrm{UK}$ and it is expected not only to reduce $\mathrm{CO}_{2}$ emissions but also to improve our environmental attitudes as a non-economic effect 3. Japanese government however has no experience to introduce $\mathrm{CO}_{2}$ emission management system when using energy. It is therefore difficult to adapt the research results in the UK directly to Japan.

The authors have proposed Feed-in Tariff PCA (FIT-PCA) suitable for Japan, which has employed the idea of German feed-in tariff rule of electricity trading 4] where the government purchases and sells the excess allowance at a fixed price. This idea can avoid the decrease of their motivations for $\mathrm{CO}_{2}$ emission management caused by the price instability in the conventional PCA systems and encourages the investment in housing equipment for reducing $\mathrm{CO}_{2}$ emission 
because they can easily design their future energy management plan. In order to investigate the public acceptance and problems of the FIT-PCA, the authors conducted a questionnaire survey [5]. As the result, the total support rate of FIT-PCA compared with an assumed down-stream Carbon Tax was $60.5 \%$. It was also found that the presentation of the average $\mathrm{CO}_{2}$ emissions of general public affects their attitudes of energy consumption. However, it has not been revealed yet about what has the effect of promoting their pro-environmental attitudes and behaviors when actually introducing FIT-PCA. The purpose of this study is to conduct a case study of FIT-PCA and to examine the effects based on the psychological model which assumes that it promotes their proenvironmental behaviors caused by the effects of loss aversion, goal setting and eudaimonia.

\section{Feed-In Tariff Personal Carbon Allowance (FIT-PCA)}

\subsection{Proposal of FIT-PCA}

Since the PCA systems studied in the UK and Nordic countries allow the citizens to trade their allowances between themselves or in the market, the management effect of $\mathrm{CO}_{2}$ emission is greatly affected by the price of allowance deals. In addition, the lives of the people who have to consume much energy may be pressured when the price becomes high. On the contrary, when the price becomes low, the motivation to reduce energy consumption and $\mathrm{CO}_{2}$ emission may be discouraged. This instability may spoil the effect of improving their pro-environmental attitudes and behaviors by managing their own $\mathrm{CO}_{2}$ emissions. In addition, such as a policy of downstream carbon tax which is the direct economic burden to the consumers has not existed in Japan until now. To solve these problems, FIT-PCA has been designed based on three principles which are simplicity, effectiveness and fairness. The details of the principles will be described as follows;

Simplicity: FIT-PCA mechanisms must be comprehensive and the procedure must be simple. Because the ideas of imposing a constraint on $\mathrm{CO}_{2}$ emissions is relatively new and current emission trading system is applied only to companies, it is unfamiliar to the public at present.

Effectiveness: FIT-PCA should be effective for the citizens to improve their pro-environmental attitudes and behaviors. This is the main purpose of this policy. It is also expected to give a good influence to solve other social issues because its affected fields can be broad.

Fairness: FIT-PCA should not cause the feeling of unfairness because it is applied to various kinds of people who live in various areas and situations such as ages, number of family members, climates of residential areas and house forms, and these varieties affect the amount of $\mathrm{CO}_{2}$ emissions. FIT-PCA needs compensatory rules to reduce such unbalance caused by the varieties. 


\section{$2.2 \quad$ Rule Details}

Figure 1 shows the basic flow of FIT-PCA.

(i) Government distributes free personal carbon allowance (PCA) to the citizens periodically and equally. Here the PCA means how people have the right of $\mathrm{CO}_{2}$ emission when they consume energy in their daily lives.

(ii) They have to redeem the PCA when they purchase or consume energy such as electricity, gas, gasoline, light oil and heating oil which originate in fossil fuels.

(iii) If they don't have enough PCA when purchasing the energy, they have to also purchase the shortage of PCA for a fixed price.

(iv) They can sell the excessive PCA to the government for a fixed price if they don't need it. In this system, they have to manage their $\mathrm{CO}_{2}$ emission by their energy consumption and it is expected not only that they reduce their energy consumption and $\mathrm{CO}_{2}$ emission but also that their pro-environmental attitudes and behaviors are fostered.

The PCA is transferred to all the individual PCA accounts equally without charge at the beginning of each month. The amount is one-twelfth of annual amount decided based on the annual average of $\mathrm{CO}_{2}$ emission per person. The account is allowed to be kept for 12 months including the distribution month (banking system). The PCA which exceeds 12 months will be expired and disappears from the account. Due to this rule, the government would be able to prevent from weakening the effect of PCA management after the next fiscal year. The PCAs which are distributed to children should be managed by their parents or protectors. And the transfer and integration of PCA inside the same household is allowed because the energy consumption of their daily lives is often managed by their household units.

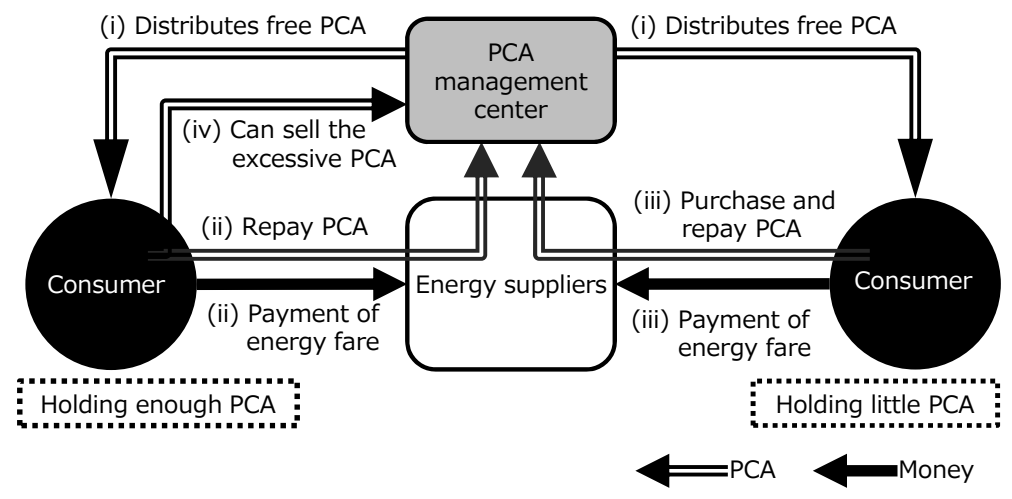

Fig. 1. Flow of FIT-PCA 


\subsection{Psychological Model of FIT-PCA}

In order to examine whether FIT-PCA encourages eco-friendly behaviors and attitudes or not, this study have assumed a model of its psychological effect as shown in Figure 2. This model is based on four theories: loss aversion, goal setting, eudaimonia and self-perception.

\section{Loss Aversion}

The loss aversion is employed from the prospect theory [6]. It refers to their strong tendency to avoid losses comparing with to make profit. This tendency is influenced by the price or a length of time. Although the price of PCA is not so expensive in the FIT-PCA, the authors expect that the loss aversion would play an important role to improve their $\mathrm{CO}_{2}$ management.

\section{Goal Setting}

Locke claimed that the goal setting affects their motivation and performance [7]. In the FIT-PCA, the amount of distributed PCA is set considering the average of $\mathrm{CO}_{2}$ emission from their daily lives. Therefore, the following effects can be expected.

1. Rational target: The target performance is better if there is a difficulty. However, it requires the rational reason.

2. Clear goal: A clear and specific goal can foster high motivation.

3. Effect of feedback: When the feedback is combined with the target setting, it improves their motivation.

\section{Eudaimonia}

The gEudaimoniah is a Greek word associated with Aristotle. This is the highest human good state of well-being and prosperous [8]. You will feel the eudaimonia when you are living well in our society. In the FIT-PCA, the authors expect the person who makes an effort to reduce $\mathrm{CO}_{2}$ emission would feel the eudaimonia.

\section{Self-perception}

This is one of the theories on behavior mechanism. Bem claimed people develop their own attitudes, beliefs, and other internal states by observing their own behaviors [9]. Therefore, in the FIT-PCA, participants may have developed their attitude by observing their own behaviors reducing $\mathrm{CO}_{2}$ emissions. And they maybe perceive their own behaviors in connection with global environmental issues. This expectation can be also explained by cognitive dissonance theory [10].

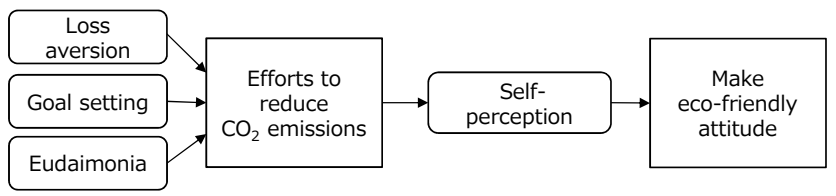

Fig. 2. Psychological model of FIT-PCA 


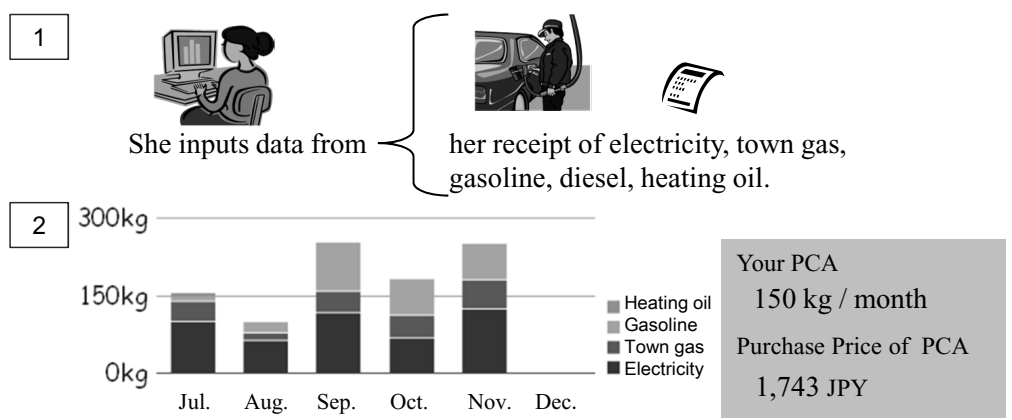

She checks her $\mathrm{CO}_{2}$ emissions and the balance of allowance.

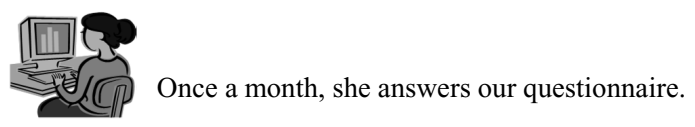

Fig. 3. Overview of case study

\section{A Case Study of FIT-PCA}

\subsection{Purpose of Case Study and Its Outline}

The purpose of this study is to examine the effects which improve their attitudes and behaviors to reduce $\mathrm{CO}_{2}$ emission when FIT-PCA is introduced in their lives. In this study, therefore, a case study has been conducted for a half year in cooperation with 30 households to investigate how they have changed their energy saving behaviors and attitudes on global environmental issues when FITPCA has been marginally introduced. Figure 3 shows an overview of this case study. In the case study, a web system has been developed which realizes PCA accounts virtually. The participants cansee the information about not only their balance of PCA but also bar graphs of $\mathrm{CO}_{2}$ emissions with general average line (this is a distributes PCA/month) in this web system. The overall procedure of the case study is shown below;

1. The participants input their energy consumption data which they used in the household to the web system when they pay for the energy.

2. They check their $\mathrm{CO}_{2}$ emissions and the balance of PCA.

3 . They answer the questionnaire once a month in order to examine the change of their attitudes and behaviors.

4. The above 1-3 is repeated for six months (From July to December 2012).

In this study, the reward to be paid to the participants is changed depending on how they trade their PCA in order to realize its economic effect. In addition, the participants have been divided into two PCA price groups, $1 \mathrm{JPY} / \mathrm{kg}-\mathrm{CO}_{2}$ and $10 \mathrm{JPY} / \mathrm{kg}-\mathrm{CO}_{2}$ in order to examine the effect of loss aversion. 


\subsection{Methods of Case Study}

The participants of the case study participants can understand their balance of $\mathrm{CO}_{2}$ emissions and PCA of the month by inputting the amount of their consumed energy to FIT-PCA account inventory (FAI). In this case study, the amount of PCA which was distributed to the participants was set $150 \mathrm{~kg}-\mathrm{CO}_{2} /$ month. It is because the average of $\mathrm{CO}_{2}$ emissions by Japanese household per capita is 167 $\mathrm{kg}-\mathrm{CO}_{2} /$ month approximately [11] and the distributed PCA should be a little lower than the average to promote their $\mathrm{CO}_{2}$ emission reduction. Formula (1) shows a calculation of $\mathrm{CO}_{2}$ emissions $G$ in FAI.

$$
G=\frac{p_{i} c_{i} E_{i}}{n}
$$

Where $p$ is the proportion of energy use in their household against their business, $c$ is the emission factor by energy source, $E$ is the energy consumption, $n$ is the number of people per household and $i$ is the type of energy. Table 1 shows the $\mathrm{CO}_{2}$ emission factors of energy [12].

Table 1. $\mathrm{CO}_{2}$ emission factors by energy types

\begin{tabular}{lll} 
Type of energy & \multicolumn{2}{c}{$\mathrm{CO}_{2}$ emission factor } \\
\hline Electricity $[\mathrm{kWh}]$ & $@ 0.559$ & {$\left[\mathrm{CO}_{2}-\mathrm{kg} / \mathrm{kWh}\right]$} \\
Town gas $\left[\mathrm{m}^{3}\right]$ & $@ 2.23$ & {$\left[\mathrm{CO}_{2}-\mathrm{kg} / \mathrm{m}^{3}\right]$} \\
Gasoline $[l]$ & $@ 2.32$ & {$\left[\mathrm{CO}_{2}-\mathrm{kg} / \mathrm{l}\right]$} \\
Light oil $[l]$ & $@ 2.58$ & {$\left[\mathrm{CO}_{2}-\mathrm{kg} / \mathrm{l}\right]$} \\
Heating oil $[l]$ & $@ 2.49$ & {$\left[\mathrm{CO}_{2}-\mathrm{kg} / \mathrm{l}\right]$}
\end{tabular}

In this case study, the questionnaire surveys have been conducted at beginning of each month. In the questionnaire, the authors have set the questions about the each element of FIT-PCA psychological model and the change of attitude to the global environmental issues. The participants answered each question as a five grade likert-scale for later quantitative analysis. In addition, the sixth choice of gdo not knowh is set in some questions where there is a possibility that the participants cannot understand the meaning of the questions. Furthermore, interviews to the participants will be carried out at the end of the case study period in order to confirm their detail psychological changes and their reasons.

\subsection{Results of the Case Study}

In order to examine whether there is a difference of the loss aversion by the different price of PCA or not, the participants were divided into two groups of 1 $\mathrm{JPY} / \mathrm{CO}_{2}-\mathrm{kg}$ and $10 \mathrm{JPY} / \mathrm{CO}_{2}-\mathrm{kg}$ as the price of PCA. Table 2 shows the result of independent t-test which shows the difference between the $1 \mathrm{JPY} / \mathrm{CO}_{2}-\mathrm{kg}$ and $10 \mathrm{JPY} / \mathrm{CO}_{2}-\mathrm{kg}$ groups' answers about loss aversion gI want to reduce the loss by purchasing PCA as much as possibleh. In the questionnaire of all case studies' period, there is no significant difference between these groups. In other 
Table 2. Result of t-test which shows the difference of the loss aversion between 1 $\mathrm{JPY} / \mathrm{CO}_{2}-\mathrm{kg}$ and $10 \mathrm{JPY} / \mathrm{CO}_{2}-\mathrm{kg}$ groups

Questionnaire period Group mean value $S D$ t-statistic $d f$ Two-sided $\mathrm{P}$ value

\begin{tabular}{|c|c|c|c|c|c|c|}
\hline Early August & $\begin{array}{l}1 \text { JPY } \\
10 \mathrm{JPY}\end{array}$ & $\begin{array}{l}4.07 \\
4.20\end{array}$ & $\begin{array}{l}1.15 \\
0.95\end{array}$ & 0.35 & 25 & 0.73 \\
\hline Early September & $\begin{array}{l}1 \text { JPY } \\
10 \mathrm{JPY}\end{array}$ & $\begin{array}{l}4.27 \\
3.93\end{array}$ & $\begin{array}{l}0.80 \\
1.17\end{array}$ & 0.94 & 26 & 0.35 \\
\hline Early October & $\begin{array}{l}1 \text { JPY } \\
10 \mathrm{JPY}\end{array}$ & $\begin{array}{l}4.07 \\
4.27\end{array}$ & $\begin{array}{l}1.18 \\
0.58\end{array}$ & 0.61 & 26 & 0.55 \\
\hline Early November & $\begin{array}{l}1 \text { JPY } \\
10 \mathrm{JPY}\end{array}$ & $\begin{array}{l}4.33 \\
4.20\end{array}$ & $\begin{array}{l}1.07 \\
0.86\end{array}$ & 0.39 & 26 & 0.70 \\
\hline Early December & $\begin{array}{r}1 \mathrm{JPY} \\
10 \mathrm{JPY}\end{array}$ & $\begin{array}{l}4.07 \\
4.20\end{array}$ & $\begin{array}{l}1.08 \\
0.80\end{array}$ & 0.59 & 25 & 0.56 \\
\hline
\end{tabular}

Question: Do you want to reduce the loss by purchasing PCA as much as possible? This questionnaire uses a likert scale. 1:No, 5:Yes

words, it was found that loss aversion has not been affected by the difference of PCA price. And this result can increase the feasibility of FIT-PCA because it is easier to obtain public acceptance when introducing low price FIT-PCA.

In order to examine whether FIT-PCA has led to the participants' efforts to reduce $\mathrm{CO}_{2}$ emissions by the loss aversion, the goal setting and the eudaimonia as shown in Figure 2, a multiple regression analysis was made. Figure 4 shows the path diagram based on the results. As shown in the figure, it was found that the efforts to reduce $\mathrm{CO}_{2}$ emissions has significantly affected by the goal setting or the eudaimonia. Table 3 shows the number of the participants who perceived their own attitude to global environmental issues. This result shows the people who made efforts to reduce $\mathrm{CO}_{2}$ emissions tended to perceive their own attitudes to be eco-friendly. Table 4 shows the changes of the attitudes to the environment which are their risk perception, effectiveness and responsibility attribution. This result shows their attitudes to global environmental issues have been improved comparing with before the case study.

\subsection{Discussion}

As shown in Figure 4, the results of multiple regression analysis show the goal setting or eudaimonia have improved the gmake efforts to reduce $\mathrm{CO}_{2}$ emissionsh. It is supposed that the loss aversion have not affected it directly because the participants have not been able to imagine which activity saves a loss in daily lives from FAI. In summer and winter, they tended to be conscious of their goals because they have consumed more energy and PCA in these seasons and they have been forced to be aware of the rest of their PCAs. On the other hand in autumn, it is supposed that they could feel endaimonia because they have enough margins of their PCAs. 

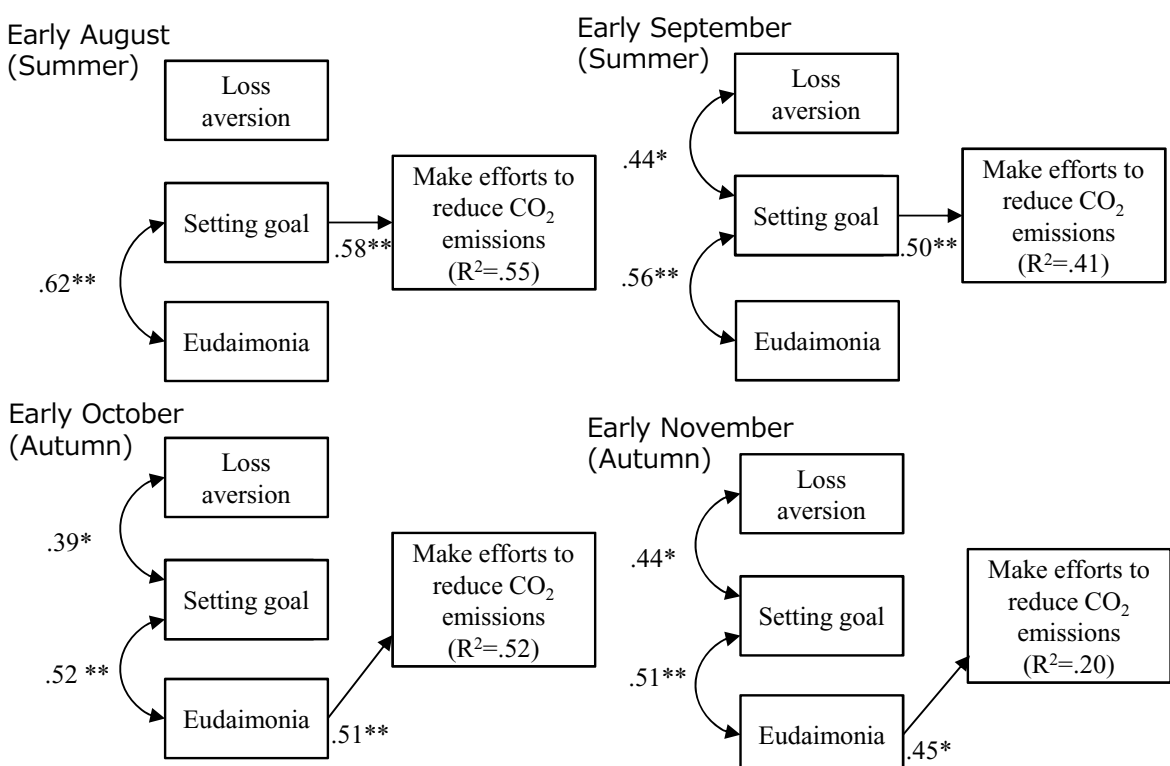

Early November

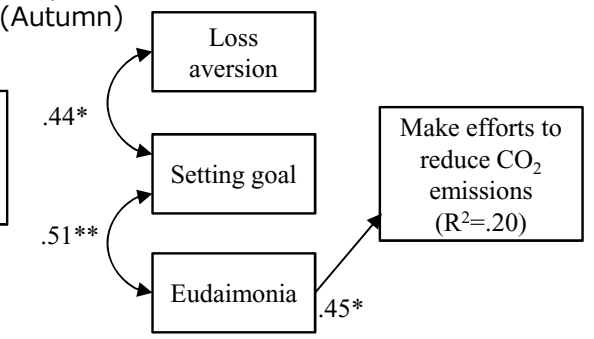

Early December
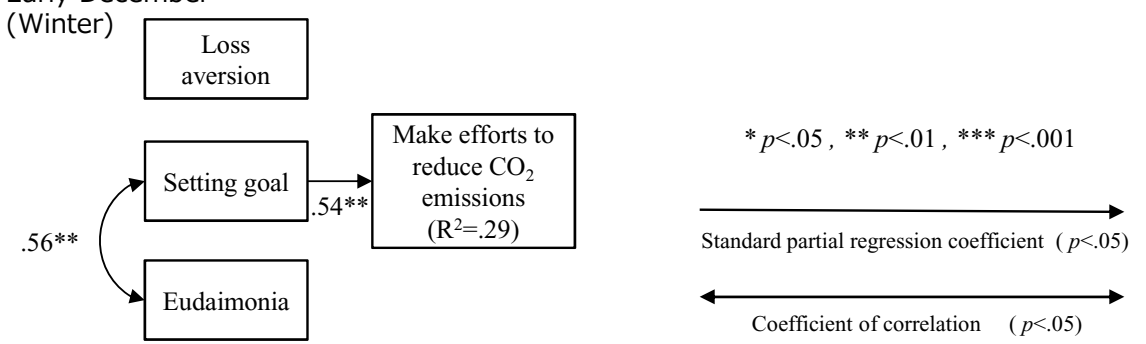

Fig. 4. Path diagrams of FIT-PCA psychological model

Table 3. The number of the participants who perceived their own behaviors in connection with global environment

Questionnaire Make efforts to reduce Perceive their own attitude to period $\quad \mathrm{CO}_{2}$ emissions $[n] \quad$ global environment issues $[n]$

\begin{tabular}{lll}
\hline Early August & 10 & 6 \\
Early September & 11 & 8 \\
Early October & 11 & 7 \\
Early November & 12 & 8 \\
Early December & 10 & 9
\end{tabular}


Table 4. Changes of the attitudes to the environment (The people who have perceived their own attitude to global environmental issues in early December)

\begin{tabular}{|c|c|c|c|c|c|}
\hline Attitude & Questionnaire period & Mean value & $S D$ & $d f$ & t-statistic \\
\hline \multirow{2}{*}{ Risk Perception } & Before case study & 3.22 & 1.09 & \multirow{2}{*}{8} & \multirow{2}{*}{$2.26^{*}$} \\
\hline & Early December & 4.22 & 0.833 & & \\
\hline \multirow{2}{*}{ Effectiveness } & Before case study & 1.22 & 0.441 & \multirow{2}{*}{8} & \multirow{2}{*}{$2.00^{*}$} \\
\hline & Early December & 1.89 & 0.928 & & \\
\hline \multirow{2}{*}{$\begin{array}{l}\text { Responsibility } \\
\text { attribution }\end{array}$} & Before case study & 3.00 & 1.07 & \multirow{2}{*}{7} & \multirow{2}{*}{1.69} \\
\hline & Early December & 2.13 & 0.991 & & \\
\hline
\end{tabular}

\section{Conclusion}

In this study, the authors have assumed a psychological model of FIT-PCA and have validated it through a case study. Since the case study is still under progress, some intermediate results were reported in this paper. For example, the loss aversion effect has not been different by the difference of PCA price. Setting goal and eudaimonia have led the participant to their efforts to reduce $\mathrm{CO}_{2}$ emissions. Furthermore, there was a tendency to express that their $\mathrm{CO}_{2}$ reduction behaviors were based on their global environmental attitudes. This is supposed to be caused by their self-perception. Since the potential of FIT-PCA is dependent on the individual needs for $\mathrm{CO}_{2}$ emissions, the authors will clarify its effectiveness in this case study analysis.

Acknowledgement. This work was partly supported by an "Energy Science in the Age of Global Warming" of Global Center of Excellence (G-COE) program (J-051) of the MEXT of Japan.

\section{References}

1. Ministry of Environment: Japan's National Greenhouse Gas Emissions in Fiscal Year 2010 (Final Figures) (2012), http://www.env.go.jp/en/headline/headline.php?serial=1763 (accessed February 20, 2013)

2. Howell, R.: Living with a carbon allowance: The experiences of Carbon Rationing Action Groups and implications for policy. Energy Policy 41, 250-258 (2012)

3. Fawcett, T.: Personal carbon trading: A policy ahead of its time? Energy Policy 10(4), 369-384 (2010)

4. Huenteler, J., et al.: Japan's post-Fukushima challenge-implications from the German experience on renewable energy policy. Energy Policy 45, 6-11 (2012)

5. Kitamura, T., et al.: A Proposal of Feed-in Tariff Personal Carbon Allowance (FITPCA) and its Evaluation. In: Symposium on Socially and Technically Symbiotic Systems (STSS 2012), Okayama, Japan, pp. 281-288 (2012)

6. Kahneman, D., Tversky, A.: Prospect Theory: An Analysis of Decision under Risk. Econometrica 47(2), 263-291 (1979) 
7. Locke, E.: Toward a theory of task motivation and incentives. American Institutes for Research 3(2), 157-189 (1968)

8. Waterman, A.: Two conceptions of happiness: Contrasts of personal expressiveness (eudaemonia) and hedonic enjoyment. Journal of Personality and Social Psychology 64, 678-691 (1993)

9. Bem, D.: Self-perception theory. Advances in Experimental Social Psychology 6, $1-62(1972)$

10. Festinger, L.: A theory of cognitive dissonance. Stanford Univ. Press, Stanford (1997)

11. Greenhouse Gas Inventory Office of Japan: The GHGs Emissions Data of Japan (1990-2010) (2012), http://www-gio.nies.go.jp/aboutghg/nir/nir-e.html (accessed February 20, 2013)

12. Ministry of Environment: The system of reporting of carbon dioxide equivalent greenhouse gas emissions (2006), http://ghg-santeikohyo.env.go.jp (accessed February 20, 2013) 